\title{
Phosphorus Reduction from Urban Wastewater Treatment Plant with Trickling Filters
}

\author{
Faruk Hajrizi ${ }^{1}$, Shefqet Rashani ${ }^{2}$, Spiro Drushku ${ }^{3}$, Rasim Veseli ${ }^{4}$, Shehide Kaqkini-Hajrizi ${ }^{5}$ and Sadete Hajrizi ${ }^{4}$ \\ 1. Regional Water Company Mitrovica, Mitrovica 40000, Republic of Kosovo \\ 2. Departmernt of Technology, University of Mitrovica, Mitrovice 40000, Republic of Kosovo \\ 3. Department of Industrial Chemistry, University of Tirana, Tirana 1000, Republic of Albania \\ 4. Department of Public Services, Municipality of Mitrovica, Mitrovice 40000, Republic of Kosovo \\ 5. Nestle Suisse S. A., Rorschach 9401, Switzerland
}

\begin{abstract}
The purpose of this research is to investigate a biofilm system with trickling filter as a biological alternative process during low cost treatment connection with the possibility of reducing nutrients such as phosphorus. Given that nitrogen with phosphorus that are leading causes of algal bloom resulting in increased eutrophication or chemical nutrients are the basis of this document analysis. This increase in organisms results in less oxygen in water bodies and at times, slow decay leads many fresh water ponds, lakes and rivers. The process of eutrophication unfortunately tends to favor pollution and algae, which reduce the quality of the water. Kosovo has not a long tradition in the treatment of wastewater, especially in removing phosphorus, since the country has only a plant for wastewater treatment. The present plant is intended to protect the Klina river from eutrophication from wastewater discharged after treatment. This plant currently reduced phosphorus efficiently, but the goal of this paper is to increase the percentage of removal of phosphorus to $40 \%$ through trickling filters, presenting options for optimizing work on plant Skenderaj.
\end{abstract}

Key words: Wastewater, trickling filters, phosphorus removal, eutrophication.

\section{Introduction}

Phosphorous effect when located in high quantities which is associated has a direct supply of piped water. During the summer months, there is an increase of aquatic organisms, such as algae that leave unpleasant smell. Phosphorus together with nitrogen is the main cause of the algae bloom resulting in eutrophication or an increase of chemical nutrients [1].

Phosphorus as one of wastewater nutrients can be found in numerous forms which can be treated in different ways. The main forms in which phosphorus is found in wastewater are organic phosphates, pyrophosphates and orthophosphates three-poly-phosphates. Ways to remove these numerous forms of phosphorus made through different

Corresponding author: Faruk Hajrizi, Ph.D., research field: chemical treatment processes of industrial and urban waste-water. E-mail: farukhajrizi@gmail.com. technologies, including chemical precipitation methods, assimilation biological and physical filtration.

Reducing phosphorous through biological process is realized in the treatment plant wastewater in Skenderaj (Fig. 1), in which the reservoir aerobic trickling filtrate and sedimentation tank (imhoff tank) carry the main burden of this reduction phosphorus, where fermentation occurs and acetates produce. Imhoff tank reduced the amount of phosphorus by $5 \%-10 \%$.

The biological phosphorus removal at the plant made the microbiological method to remove phosphorus from wastewater by means of phosphate accumulating bacteria (Fig. 2). These aerobic bacteria are not only able to form normal amount of phosphorus needed for cell growth, but also take up additional phosphorus in the form of polyphosphate in the cell-the so-called "luxury uptake". Increasing in organisms results in 


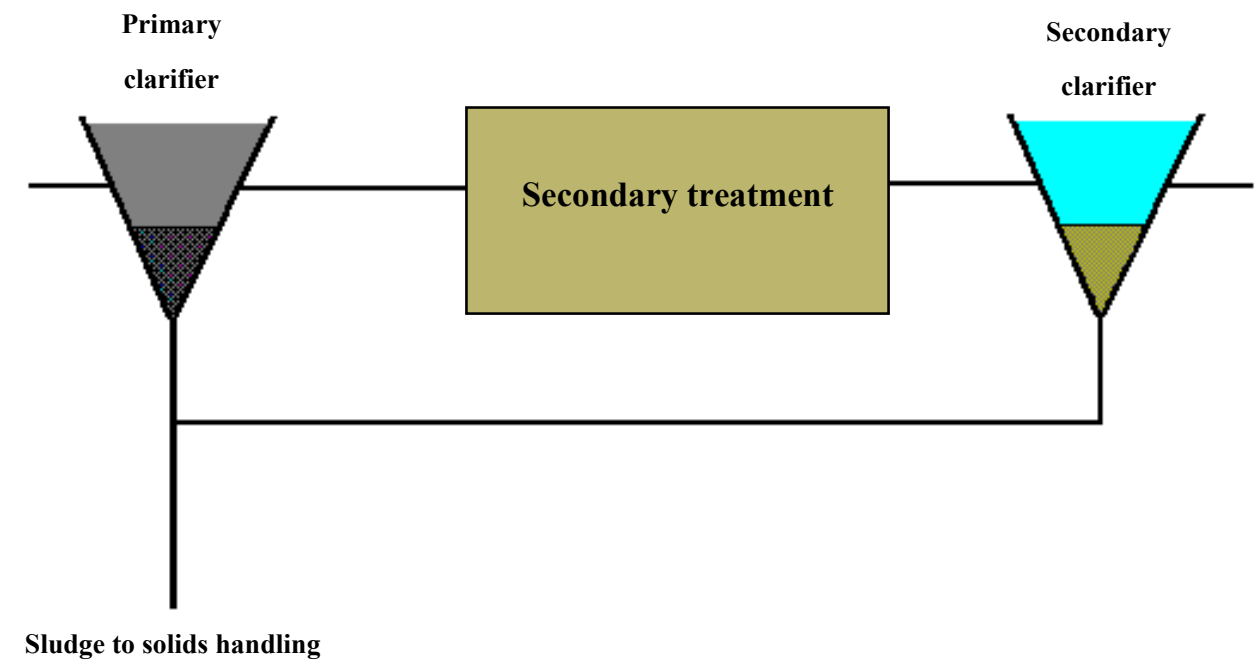

Fig. 1 Scheme of biological treatment system in Skenderaj.

less oxygen in water bodies and at times, slow decay leads many fresh water ponds, lakes and rivers [2].

Phosphorus is normally removed by precipitation, but in order to reduce the need to use chemicals, which are costly, and reduce the production of sludge, biological removal of secondary treatment is an option [3]. Special bacteria, called phosphate accumulating organisms, briefly assimilate volatile fatty acids and store them in the cell. To release the energy, it is needed orthofosfateve $\left(\mathrm{O}-\mathrm{PO}_{4}\right)$ divided by increasing the concentration of phosphorus in water. This happens in an anaerobic environment. When organisms reach an aerobic environment, metabolism, oxidation of organic matter releases energy and enables the connection of phosphate in cells of bacteria. Due to the presence of phosphorus stored in the waste, sludge net effect will be a reduction of phosphorus dissolved in water. To have a high degree of removal of phosphorus, it needs a high concentration of volatile fatty acids and an anaerobic environment without oxygen or nitrate [4]. Incoming wastewaters containing some volatile fatty acids and more wastewater septic (infected), collection systems from warmer climates, will contain high concentrations of volatile fatty acids. Process briefly favors keeping solids, which could be contrary to the longtime of keeping the solids required to conduct the removal of nitrogen.

Making washing of dishes from different vessels and hand soap along other forms of washing detergents that are free of phosphorus compounds helps prevent additional $\mathrm{P}$ from entering the water supply. When trying to reduce high levels of community, it should not depend entirely on plants to treat wastewater.

\section{Methods and Materials}

Wastewater treatment plant in Skenderaj is designed and works with attached growth process that is configured with two zones connected in series - the first is anaerobic reservoir Imhoff aerobic area and the second is aerobic area [5]. Phosphorus fixing organisms, who possess a capacity metabolic particular not widely found in bacteria, they will multiply and accumulate large amounts of inorganic phosphate as polyphosphate, allowing the removal of phosphorus from wastewater by removing biomass. Although organisms fixing phosphorus are usually present with a number of systems to increase the suspenseful completely aerobic, they develop the ability to accumulate large amount of phosphate only when they are subject of alternating anaerobic and aerobic being recycled between the two areas [6]. This 
stems from their unique ability to accumulate carbon price of phosphate removal under anaerobic conditions and maintain phosphate price of carbon removal under aerobic conditions.

As a result of fermentation, many dissolved organic matter in urban waste water in the form of acetate and other fatty acids have shorter range. Furthermore, when wastewater entered an anaerobic reactor, other quantities of fatty acids would be formed as a result of the fermentation reactions conducted by heterotrophs optional [7]. Acetate is transported through the cell membrane by passive diffusion (such as acetic acid undivided), but when you go inside, it is activated in the form of acetyl-CoA realizing ATP hydrolysis and produced ADP. Although not shown in the diagram, ATP is also used to keep the proton-motive force which lost from the transport of protons and associated with the without ionizing acetic acid. Cells respond to lowering the ratio ATP/ADP stimulating ATP re-synthesis by polyphosphates (poly-pn) accumulated. A portion of the acetyl-CoA is metabolized through the TCA cycle to provide reducing power $\left(\mathrm{NADH}+\mathrm{H}^{+}\right)$required for the synthesis of PHB. The remainder of acetyl-CoA converted to PHB (poly- $\beta$-lipid hidroksi-butirate), with about $90 \%$ of carbon stored as polymer acetate. In the absence of the polyphosphates which provide energy for re-synthesis of ATP, acetate will be created in the cell, transport of acetate will stop and will not happen PHB's formation. Polyphosphates by hydrolysis of ATP increases inorganic phosphate concentration intercellular, $\mathrm{Pi}$, which is released into the solution of greater quantity, with cations (not shown) to keep the load balanced.

When associated wastewater and biomass entering the aerobic area, contaminated water has small amounts of dissolved organic matter, but phosphorus fixing organisms contain large reserves of PHB's. Furthermore, polluted waters are rich with inorganic phosphate, whereas, the phosphorus fixing organisms have small concentration of polyphosphate. Because
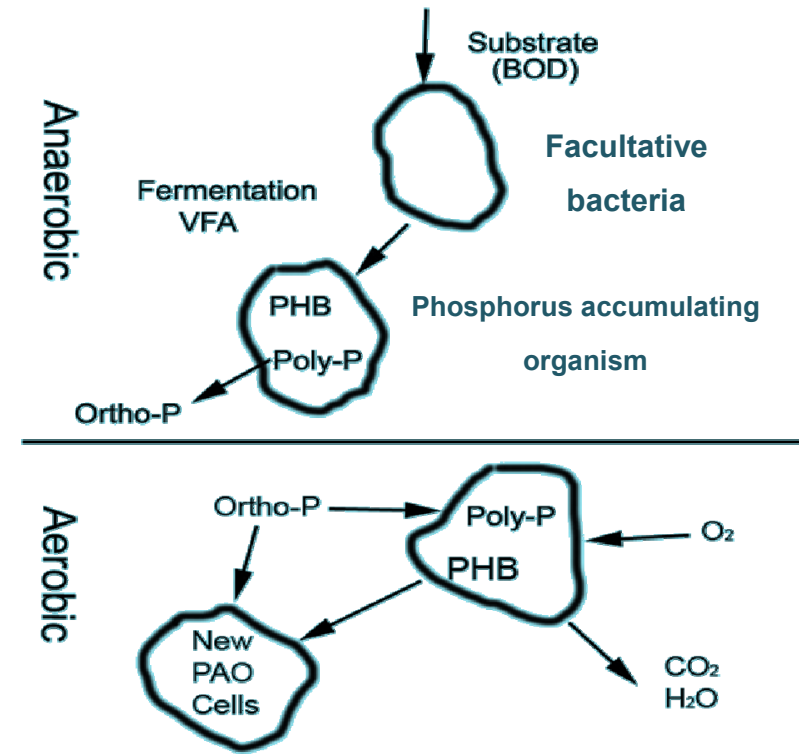

Fig. 2 The process of reducing phosphorus from wastewater treatment.

they use oxygen as electron receivers in the aerobic organisms perform for fixing phosphorus normal increase aerobic metabolism using PHB's reserves as a source of carbon and energy and producing ATP through phosphorylation electron carrier [8].

Since the report of ATP/ADP increases, it stimulated polifosfatit synthesis, thereby, removing phosphate and related cations (not shown) from the solution and regenerating stocks phosphate cell. As a result of the large amount of energy provided by metabolism aerobic of PHB's pooled organisms fixing phosphorus, they are able to capture all phosphate release in the anaerobic zone plus phosphate present at the outset in polluted waters.

Turnover continued between areas anaerobic and aerobic gives PAOs (organisms fixing phosphorus) an advantage against bacteria other heterotrophs, because without the ability to produce and use polyphosphate, heterotrophs ordinary are not able to capture organic matter in the anaerobic zone. It should be noted that while the vast majority of systems that divert phosphate through the use of PAOs use areas, aerobic regeneration polyphosphates accumulate some PAOs can use nitrate and nitrite as making alternative electrons, allowing even use anoxic conditions. 


\section{Results and Discussion}

To analyze the amount of wastewater pollution is necessary to control and monitor the work of the functional units and the plant itself entirely. The findings and conclusions on the functioning of the plant are based on the parameters of load which is projected to achieve water quality output as per plant designing, and in this paper, they are focused on the monitoring of phosphorus in wastewater of the Skenderajt.

In the Fig. 3, experimental measurements during a year in Skenderaj operations are presented. Phosphorus compounds are found in various forms in waste water, one being orthophosphate $\left(\mathrm{HPO}_{4}{ }^{2-}\right)$ that can be determined in water without decomposition prior. Organic and inorganic phosphate compounds, which are known collectively as total phosphate, can be determined after decomposition. All of these phosphorous compounds must be included in an accurate study of process water. The tests cover the aquanaltm phosphate concentrations of phosphate. A factor is used to calculate the concentration of phosphorus.

\section{Conclusions}

Removal or reduction of phosphorus from wastewater represents one of the most important processes though done against pollution of water treatment, especially in the case of artificial lakes and reservoirs, the excessive burden of this compound in aquatic ecosystems can lead to eutrophication.

Despite the limitation of phosphorus, load of phosphorus discharged to municipal sewage must be removed from the plant wastewater advanced high effective. Phosphorus removal mechanisms with both chemical and biological methods are not fully known, particularly in Kosovo. This is why it will be widely investigated in the coming future.

Removing phosphorus from wastewater can be done with biological and chemical processes, the selection process depends on different grounds. In Skenderaj, it is selected biological treatment of type drip filters according to monitoring results which shows that the removal of phosphorus is on average $50 \%$ equal to more than $2 \mathrm{mg} / \mathrm{L}$. According to standards, it should be removed over $80 \%$ of total P (2 $\mathrm{mg} / \mathrm{L}$ ), and is recommended in the process to intervene with chemical precipitation method and achieved reduction conform restrictions. Future treatment technologies provide a range of phosphorus removal which allows recycling phosphorus as a fertilizer and directing it back to nature will be granted.

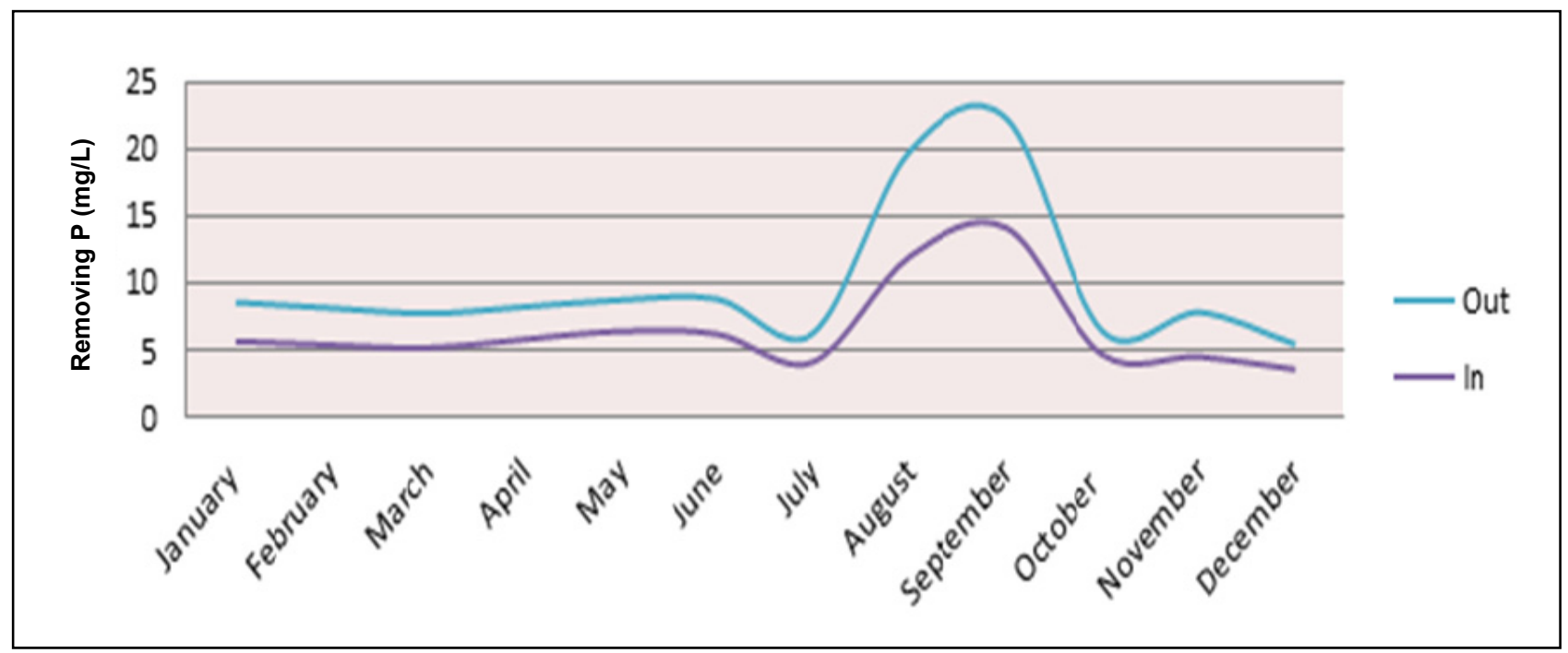

Fig. 3 Removing phosphorus from wastewater in Skenderaj during 2014. 


\section{References}

[1] Crites, R., and Tchobanoglous, G. 1998. Biological Treatment and Nutrient Removal. USA: WCB McGraw Hill.

[2] Zhou, L., Bai, X., and Li, Y. 2008. "Immobilization of Micro-organism on Macro Porous Polyurethane Carriers." Environ. Eng. Sci. 25 (9): 1235-1241. doi:10.1089/ees.2007.0220.

[3] Barnard, J. 1975. "Biological Nutrient Removal without Addition of Chemicals." Water Research 9: 485-490.

[4] Zhu S., and Chen, S. 2002. "The Impact of Temperature on Nitrification Rate in Fixed Film Biofilters." Aquacult. Eng. 26 (4): 221-237.
[5] Henze, M., Van-Loosdrecht, M. C. M., Ekama, G., Brdjanovic, D. 2008. Biological Wastewater Treatment: Principles, Modelling and Design. London: IWA Publishing.

[6] Moller, S., Korber, D. R., Wolfaardt, G. M., Molin, S., and Caldwell, D. E. 1997. "Impact of Nutrient Composition on a Degradative Biofilm Community." Appl. Environ. Microbiol. 63: 2432-2438.

[7] Metcalf, L., and Eddy, H. P. 1991. Wastewater Engineering: Treatment, Disposal and Reuse. New York: Mc-Graw-Hill.

[8] Mino T., Van-Loosdrecht, M. C. M., and Heijnen, J. J. 1998. "Microbiology and Biochemistry of the Enhanced Biological Phosphorus Removal Process." Water Res. 32: 3193-3207. doi:10.1016/S0043-1354(98)00129-8. 